\title{
Tinjauan Interdisipliner dalam Mengkaji Aspek Kosmologi dalam Arsitektur
}

\author{
Ema Yunita Titisari ${ }^{1}$, Antariksa ${ }^{2}$, Lisa D.W. ${ }^{3}$, Surjono $^{4}$ \\ 1,2,3,4Fakultas Teknik, Universitas Brawijaya \\ ema_yunita@ub.ac.id
}

\begin{abstract}
ABSTRAK
Makalah ini berisi kajian mengenai pentingnya tinjauan interdisipliner dalam mengkaji aspek kosmologi pada arsitektur. Arsitektur adalah disiplin ilmu yang fokus kajiannya berhubungan dengan lingkungan tempat tinggal manusia. Lingkungan dan manusia adalah objek yang sangat kompleks. Kajian atas manusia dan arsitektur perlu melibatkan disiplin ilmu yang lain. Pelibatan disiplin ilmu lain itu akan membantu pemahaman mengenai manusia dan arsitektur sebagai produk budaya. Kosmologi menjadi kunci untuk memahami arsitektur, khususnya arsitektur masyarakat pra-modern. Melalui analisis substansi dari teori-teori dan hasil-hasil penelitian arsitektur mengenai kosmologi diperoleh kesimpulan bahwa dalam mengkaji aspek kosmologi dalam arsitektur diperlukan kajian interdisipliner karena arsitektur adalah objek yang perlu ditinjau dari banyak perspektif. Hal ini disebabkan oleh kompleksitas manusia yang membuat dan menciptakan arsitektur sebagai wadah tempat tinggalnya.
\end{abstract}

Kata kunci: interdisipliner, arsitektur, kosmologi

\section{ABSTRACT}

This paper is a review of the importance of interdisciplinary reviews in assessing the cosmological aspects of architecture. Architecture is a discipline that focuses on the study of the human environment. Environment and humans are very complex objects. Studies of people and architecture need to involve other disciplines. Involving other disciplines will help the understanding of people and architecture as a cultural product. Cosmology is the key to understanding architecture, especially the architecture of pre-modern society. By analysing the substance of some theories and architectural research on cosmology obtained the conclusion that in reviewing cosmological aspects in architecture is required interdisciplinary studies because architecture is an object that needs to be viewed from many perspectives. This is due to the complexity of human beings who create and create architecture as a place of residence.

Keywords: interdisciplinary, architecture, cosmology

\section{Pendahuluan}

Makalah ini berisi pembahasan mengenai pentingnya kajian interdisipliner dalam mengkaji kosmologi dalam arsitektur. Arsitektur adalah disiplin ilmu yang fokus kajiannya berhubungan dengan lingkungan tempat tinggal manusia. Lingkungan dan manusia adalah objek yang sangat kompleks. Pelibatan disiplin ilmu lain akan membantu pemahaman mengenai manusia dan arsitektur sebagai produk budaya. Untuk itu, makalah ini berupaya mengkaji disiplin ilmu apa sajakah yang terlibat dalam kajian mengenai aspek kosmologi pada arsitektur.

Pembahasan pada makalah ini dibagi menjadi beberapa bagian, yaitu:

a. Penjelasan mengenai kajian interdisipliner

b. Identifikasi disiplin ilmu terkait topik kajian, yang ditelusuri melalui identifikasi arti kata-kata kunci (yaitu: kosmologi dan peran kosmologi dalam arsitektur). Identifikasi kata-kata kunci ini ditelaah melalui kajian teoritik dari literatur dan hasil-hasil penelitian sebelumnya. 


\section{Kajian Interdisipliner}

Tak ada manusia yang mengetahui segala hal, bahkan dalam bidang ilmu yang ditekuninya. Budaya industri menuntut kemudahan dalam segala aspek kehidupan. Alat (teknologi) menjadi tuntutan bagi kemudahan hidup. Sejalan dengan tuntutan tersebut, pengetahuan berkembang semakin cepat dan kompleks. Kompleksitas pengetahuan ditunjukkan dengan semakin banyaknya cabang-cabang ilmu baru sehingga muncul spesialisasi-spesialisasi. Spesialisasi pengetahuan menunjukkan semakin dalamnya pengetahuan manusia mengenai suatu hal, sekaligus menunjukkan bahwa secara rasional, ada keterbatasan pengetahuan.

Kesadaran akan bahaya egoisme pengetahuan, yakni keberpihakan dan arogansi atas suatu disiplin ilmu pengetahuan tertentu dalam menyelesaikan masalah, menumbuhkan motivasi untuk mengkaji suatu masalah atau objek melalui praktek lintas batas disiplin, yakni trans-disipliner, multi-disipliner, dan inter-disipliner (Muharam 2013; Sudikan 2015). Multidisiplin yaitu ketika menyelesaikan permasalahan dari berbagai disiplin ilmu, di mana masing-masing berpijak pada disiplin ilmunya. Transdisipliner meleburkan batas-batas disiplin ilmu sehingga pada perkembangannya muncul bidang keilmuan baru yang merupakan gabungan dari dua atau lebih disiplin ilmu, misalnya: Human Ecology, Ekonomi Politik, Teknik Lingkungan, dan sebagainya. Interdisipliner berarti mengkaji suatu permasalahan dengan cara mengkombinasikan dua atau lebih disiplin ilmu sebagai alat atau perspektif kajian, tetapi peneliti tetap berpijak pada satu disiplin ilmu. Kajian interdisipliner tidak mengkhususkan diri pada alat analisis tertentu yang bersandar pada satu paradigma keilmuan tertentu, tetapi juga menggunakan bidang-bidang keilmuan lain yang relevan (Muntasyir, 2010). Multidisipliner adalah penggabungan beberapa disiplin ilmu secara bersama-sama. Batas masing-masing disiplin tetap ada, dan titik pijakan adalah pada masing-masing disiplin ilmu tersebut.

Menurut Muharram (2013), interdisiplineritas mencakup empat bidang, yaitu: pengetahuan, riset, pendidikan dan teori. Riset interdisipliner menggabungkan komponen dari dua atau lebih disiplin dalam rangka mencari pengetahuan baru, baik untuk pengkayaan pengetahuan maupun praksis. Riset interdisipliner bertujuan untuk mengeksplorasi permasalahan yang tak dapat diselesaikan melalui satu bidang ilmu saja.

Kajian interdisipliner sangat diperlukan saat ini karena peningkatan kompleksitas hubungan antara alam dan masyarakat (Kaelan 2012). Kajian interdisipliner dipahami sebagai variasi cara dalam menjembatani dan mengkonfrontasi berbagai pendekatan disiplin terkait. Menurut Muharram (2013), penganut disiplin ilmu tertentu seringkali melakukan kesalahan yang hanya bisa terdeteksi oleh orang yang memahami dua atau lebih disiplin ilmu. Pengamatan interdisipliner diperlukan karena jurang antar disiplin ilmu terlalu luas, sehingga tidak jarang ilmuwan mengambil kesimpulan yang bertabrakan dengan kesimpulan di disiplin ilmu lain akibat generalisasi atau ketidakpekaan. Peneliti disipliner dapat mengisi celah kosong yang produktif sehingga area abuabu ilmu pengetahuan bisa diisi.

Seorang negarawan bisa melakukan kesalahan karena tidak memahami aspek teknis, sosial atau alamiah dari suatu kebijakan. Ilmuwan bisa memberikan saran yang buruk, sedangkan pengambil keputusan tidak bisa membedakan mana yang baik dan buruk. Seringkali terjadi kesalahan dalam pengambilan keputusan karena rekomendasi kebijakan yang terlalu sempit oleh mereka yang memiliki pengetahuan yang luas atau sebaliknya. Dalam dunia spesialisasi, seorang berpendidikan tinggi bisa tidak menyadari 
dimensi sosial dan moral dari tindakannya. Interdisiplineritas membantu kita mengingat bahwa komponen komponen pengetahuan manusia merupakan pecahan dari keseluruhan bangunan pengetahuan.

Kajian interdisipliner juga memungkinkan fleksibilitas yang besar dalam riset, sehingga memungkinkannya untuk menikmati fleksibilitas dan kebebasan baru dalam riset dan karir. Penjelajahan di lahan yang baru juga akan menjadi pengalamanbaru yang segar bagi peneliti. Terlebih dalam rangka pembangunan yang berkesinambung-lanjutan (sustainable), kajian interdisipliner diperlukan agar pengambilan keputusan lebih setimbang.

\section{Kosmologi}

Definisi kosmologi merujuk pada pemahaman mengenai alam semesta. Teori mengenai kosmologi dikeluarkan oleh ahli-ahli filsafat seperti Socrates, Plato, Aristoteles, hingga ahli fisika modern seperti Newton dan Einstein. Masing-masing teori dapat berbeda titik beratnya karena perbedaan paradigma. Menurut paradigma rasionalistik, kosmologi adalah dunia seisinya yang wadag, terlihat jelas, nyata, dan dapat ditangkap panca indera. Kajian-kajian kosmologi yang rasionalistik-empirik ini ada yang mengarah pada kajian astronomis, yaitu mempelajari kedudukan dan pergerakan benda-benda langit yang memiliki dampak terhadap perubahan iklim, cuaca, musim, arah gerak angin, kelembaban, dan lain-lain di bumi, yang mempengaruhi aktivitas sosialekonomi.

Dari Sprajc (2009), Nelson et al (2010) dan Blanchard (2010) diketahui bahwa pengetahuan mengenai kosmologi sangat membantu bagi pengaturan siklus kegiatan masyarakat agraris. Posisi benda-benda langit dibaca sebagai petunjuk perubahan musim. Benda-benda langit, posisi, dan pergerakannya kemudian diasosiasikan dengan simbol-simbol kehidupan, dewa-dewa, dan kemumgkinan-kemungkinan yang akan terjadi (ramalan). Dalam hal ini pengetahuan empirik dijalankan bersama-sama dengan keyakinan meta-empirik kosmologi. Konsep kosmologi membentuk sistem ideologi yang akhirnya bercabang-cabang membentuk jalinan dan struktur sosial, sistem kepemimpinan (ideologi politik), sistem budaya hingga diaplikasikan dalam praksis kehidupan, salah satunya dalam wujud arsitektur. Akhirnya muncul simbol-simbol kosmologis yang terintegrasi dengan kepercayaan, sistem sos ial, dan sistem politik. Posisi, orientasi, kedudukan serta eksistensi benda-benda yang ada di alam berintegrasi dengan makna simbolik yang menunjukkan keperkasaan, kekuatan, dan lain-lain (Kak 2002, Blanchard 2010). Feng Shui, petungan Jawa, dan Hasta Kosala-Kosali Bali adalah contoh bentuk pengetahuan kosmologi yang menyatuan antara pengetahuan empirik dengan keyakinan meta-empirik (Xu, 1998; Lu Yi). Pengetahuan-pengetahuan ini jamak ditemukan dalam masyarakat agraris atau masyarakat pra-modern.

Seiring dengan berkembangnya modernisme dengan ciri khas rasionalismenya, maka keyakinan-keyakinan meta-empirik perlahan mengalami pergeseran. Ketidak-mampuan rasio membaca tanda-tanda alam yang tak terindra menggeser sebagian pengetahuan kosmologi pra-modern ke wilayah mitos dan mistisisme. Dalam kajian-kajian arsitektur, khususnya di Nusantara, kosmologi dipandang sebagai salah satu faktor pembentuk ruang (Mashuri, 2010; Sumalyo, 2001; Widayat, 2004; Widyatasari, 2002; Wesnawa, 2010; Xu, 1998; dan Kartono, 2005). Ruang sakral-profan, bentuk atap, kolom, tata ruang rumah, permukiman, dan kota adalah wujud konsep-konsep kosmologis. 


\section{Kosmologi sebagai Faktor Pembentuk Ruang (Arsitektur)}

Ruang adalah unsur arsitektur yang paling utama. Ilmu arsitektur atau lingkungan binaan adalah ilmu menata ruang. Oleh karenanya pemahaman mengenai arsitektur salah satunya adalah pemahaman mengenai ruang.

Menurut Socrates, di balik yang kasat mata terdapat 'being' yang lebih hakiki yang sifatnya universal (tidak kasat mata). 'Being' merupakan unsur metafisik. Eksistensi 'being' ini sangat kuat, karena sesungguhnya ia merupakan 'ruh' atau 'energi' (Pangarsa, 2007) suatu objek. Objek yang kasat mata merupakan 'bayangan' atau 'imitasi' dari objek yang sejati. Objek yang sejati ini berada di level ide-ide/konsep. Rapoport (1975) menyebutnya schemata. Socrates, Plato, dan Aristoteles memahami bahwa ada dua 'dunia', yaitu yang nampak dan yang tak nampak. Dunia yang nampak selalu berubah, sedangkan yang tak nampak relatif tidak berubah. Dunia yang nampak merupakan representasi abstrak dari ide-ide yang yang tak nampak. Ide-ide Socrates ini dikembangkan Plato. Terkait dengan form, Plato menyatakan bahwa substansi Form yang sesungguhnya adalah pada aras ide, sedangkan yang nampak merupakan perwujudan ide tersebut. Form bersifat atemporal dan aspatial, artinya Form tidak terkait dan tidak tergantung dengan waktu tertentu maupun ruang tertentu. Dalam kaitannya dengan ide mengenai ruang sebagai objek, maka Socrates dan Plato memandang bahwa 'ruang' yang metafisik merupakan hakekat dari ruang fisik/ ruang empirik yang kasat mata. Ruang ini dapat dipahami melalui sensation atau perasaan; bukan berasal dari pikiran tetapi dari 'extra-mental'/ rasa-perasaan. Ruang fisik/empirik merupakan imitasi ruang metafisik / meta empirik.

Lao Tzu (dalam Mc Harg, 1992) memiliki pandangan yang sama. Hakekat ruang pada sebuah jambangan adalah kekosongan yang terbentuk dari tanah liat. Pendapat Lao Tzu ini sedikit lebih mudah diterjemahkan: bahwa untuk menciptakan ruang kita memerlukan batas dan simbol fisik. Namun bukan berarti batas fisik tanah liat itu lantas menjadi satu-satunya yang dapat membentuk ruang. Karena ketika manusia mewujudkan ide ruang pada jambangan itu, sangat bisa jadi ia menggunakan bahan, model, atau bentuk yang lain. Bagi Kant, ruang adalah bentuk a priori perasaan. Manusia dapat memahami ruang hanya jika ia bisa merasakannya. Pemahaman atas suatu objek juga memerlukan konteks keruangannya. Mengabaikan konteks ruang suatu objek akan menumpulkan perasaan. Padahal dengan rasa itulah manusia memahami hakekat objek dan ruang yang menyertainya. Waktu memiliki peran penting dalam upaya identifikasi dan pemahaman atas ruang. Pemahaman atas suatu objek memerlukan konteks ruang dan waktunya, keduanya merupakan continuum yang tak terpisahkan. Ide ini terus berkembang hingga saat ini, dalam perspektif geografi (Rapoport, 1989 dan Tuan, 1979), psikologi (Lang, 1987; Barker, 1968), fisika, matematika, serta cabang keilmuan lainnya.

Dalam perspektif psikologi, pemahaman ruang dibentuk oleh persepsi. Yi Fu Tuan (1975) memberi pembedaan antara space dan place (tempat). Space digunakan untuk menyebut area yang masih belum memiliki makna khusus dalam perasaan si pengguna ruang, sedangkan place digunakan untuk menyebut ruang yang memiliki makna khusus. Di dalam place, manusia memiliki pengalaman dan aspirasi tertentu. Ruang itu sendiri masih tetap dipahami sebagai area di mana suatu objek berada (objek di sini bisa berarti manusia sebagai subyek yang mengalami ruang). Persepsi ruang berkaitan dengan rekognisi (pengenalan) tampilan fisik suatu objek, atau bagaimana interaksinya ditangkap/ dilihat/ diterima/ dirasakan. Teori psikologi ruang menyatakan bahwa ruang dapat mengontrol perilaku manusia, dan sebaliknya perilaku manusia dapat membentuk ruang. Untuk itu dikenal 4 komponen perilaku dalam membentuk ruang, yaitu: personal 
space, territoriality, privacy regulation, dan boundary control (Barker, 1968; Sanders dalam Kent 1990).

Berkaitan dengan hal tersebut di atas, batas ruang menjadi sangat relatif, tergantung pada masing-masing individu. Budaya, lantas menjadi hal yang harus dipahami ketika kita mempelajari ruang suatu kelompok masyarakat. Sistem dan tata nilai yang terangkum dalam budaya, terutama pemahaman masyarakat akan kosmos/jagat raya (system of belief) sangat menentukan bagaimana mereka berinteraksi, baik dengan sesama manusia maupun dengan alam lingkungannya, sehingga akan sangat menentukan pula bagaimana mereka memaknai ruang: personal space, teritori, ruang sakral-profan, ruang publik-privat, dsb (Pangarsa, 2007).

Pada masyarakat Batammaliba, misalnya, mereka merepresentasikan pusat semesta (axis mundi) dalam ruang pusat permukiman mereka (Blier, 1987). Ruang ini merupakan perwujudan konsep kosmologi dan system of belief mereka. Ide-ide abstrak mengenai ruang (bahwa dunia memiliki pusat) diwujudkan dalam artefak (fisik) yang lantas menjadi pusat pula bagi permukiman mereka. System of belief mereka juga mengatur interaksi sosial. Ruang menjadi ekspresi ide-ide hubungan manusia-Tuhan dan manusiamanusia lain-alam lingkungan. Perubahan kosmologi berdampak pada perubahan prinsip-prinsip utama tata ruang, dan akhirnya pada arsitektur.

Ruang bukan sekedar kontainer fisik saja. Ada dimensi lain dari ruang, dan dimensi itu justru yang banyak mendikte perwujudan dan tata ruang, yaitu dimensi kosmologis. Ruang sebenarnya adalah perwujudan fisik dari konsep-konsep mengenai place yang sudah 'dikenal' manusia. Pengalaman ruang merupakan pengalaman yang sulit direkam otak karena berada di level perasaan. Akan dianggap tidak rasional ketika jawaban pertanyaan mengapa stupa berbentuk setengah bola adalah karena hal itu mengingatkan manusia pada ruang pertama yang dialaminya, yakni rahim. Ini karena saat itu otak manusia belum bisa merekam pengalaman dan panca-indranya belum bekerja sempurna. Namun ketika muncul kenyataan bahwa ruang paling privat yang banyak diwujudkan manusia adalah ruang yang sempit, gelap namun manusia merasa nyaman di dalamnya, maka apakah bukan tak mungkin bahwa ruang itu adalah perwujudan kembali suasana ruang rahim?

Ruang merupakan salah satu konsep awal yang dipahami manusia ketika ia menyadari eksistensinya di alam semesta. Kesadaran manusia akan eksistensinya tak dapat dipisahkan dari hubungannya dengan Tuhan yang menciptakannya, dan dengan alam semesta, ruang di mana ia berada. Hubungan ketiganya membentuk konsep ruang. Ekspresi simbolik dari konsep ruang sebagai wujud hubungan manusia-Tuhan YMElingkungan (sosial dan alam) akan diejawantahkan dalam ruang huniannya, lingkup mikro hingga meso. Manusia Jawa kuno menyebutnya sebagai jagad cilik-jagad gede (mikrokosmos-makrokosmos). Istilah Aristoteles untuk perwujudan konsep (abstrak) ruang menjadi simbol (arsitektural) sebagai imitasi, di mana yang diimitasi adalah 'ruang' hubungan manusia-Tuhan-lingkungan di level konsep/ide/nilai-nilai. Karena manusia memiliki fitrah sebagai makhluk yang unik, di mana ia ditempatkan di lingkungan yang juga unik, maka simbol sebagai ekspresi konsep ruang sangat mungkin berbeda-beda; unik/khas untuk setiap kelompok/komunitas, bahkan untuk setiap individu. Di level praksis, keunikan ini menjadi salah satu petanda bagi place identity. Lantas akan muncul 'arsitektur .....' (dengan kata di belakangnya menunjukkan kelompok sosial atau kelompok komunitas).

\section{A. Displin Ilmu Terkait}


Berdasarkan pengertian-pengertian di atas, maka untuk dapat memahami aspek kosmologi dalam arsitektur, maka diperlukan studi interdisipliner. Titik pijak yang digunakan adalah arsitektur, sedangkan disiplin ilmu lain yang terkait adalah:

a. Filsafat

Pendekatan filsafat diperlukan untuk memahami arsitektur di tingkat mentifact. Pemahaman ini diperlukan untuk membaca fenomena. Aspek meta-empirik kosmologi juga merupakan objek yang banyak dikaji oleh disiplin ilmu filsafat.

b. Astronomi, geografi

Para arkeolog Amerika seperti Sprajc dan Nelson belajar mengenai astronomi untuk memahami kosmologi Suku Maya. Feng Shui yang merupakan kosmologi China melibatkan pengetahuan geografi (geomancy). Kemungkinan disiplin ilmu ini juga akan dilibatkan dalam memahami fenomena arsitektur pada objek kasus, meskipun sifatnya masih tentatif, tergantung fokus dan kedalaman substansi kajian yang dilakukan.

c. Psikologi

Bagian ilmu psikologi yang termasuk dalam kajian arsitektural adalah yang berhubungan dengan hubungan manusia dengan lingkungan (psikologi lingkungan, environment-behaviour research). Disiplin ilmu ini diperlukan untuk 'membaca' fenomena arsitektur melalui pendekatan hubungan manusia dan lingkungan, sebelum ditarik lebih jauh ke level sociofact dan mentifact.

d. Antropologi

Cabang ilmu antropologi yang terlibat adalah aspek budaya yang berhubungan dengan penciptaan wadah sebagai ruang kegiatan beserta dinamikanya. Budaya merupakan unsur yang memberi pengaruh besar dalam arsitektur.

e. Sosiologi

Bagian ilmu sosial yang terkait adalah hubungan individu-individu dalam masyarakat. Bagaimana hubungan manusia dengan manusia lain, struktur yang terbentuk, dan lain-lain yang pada akhirnya diekspresikan dalam ruang. Hubungan manusia sebagai makhluk sosial ini merupakan cermin hubungan manusia-Tuhan sesuai keyakinan kosmologisnya.

f. Sejarah

Pendekatan historis (sejarah) digunakan ketika data-data yang dibutuhkan adalah data-data masa lalu, termasuk misalnya sejarah kampung, konstruksi konsep ruang dan perkembangannya, dan sebagainya. Kajian ini pasti dilibatkan karena adanya kontinuum ruang dan waktu. Arsitektur tak dapat lepas dari keterkaitannya dengan ruang di sekitarnya, juga dengan masa lalunya. Fenomena yang dapat ditangkap saat ini merupakan hasil dari proses yang terjadi di masa lalu, dan mungkin masih berlajut hingga saat ini.

g. Hermeneutika

Pendekatan ini diperlukan untuk mengungkapkan makna dari simbol-simbol kosmologi yang ada pada arsitektur (Badillo 2011). Sebagai homo simbolicus (Pangarsa, 2007), manusia selalu membuat simbol untuk mengekspresikan konsep-konsep abstrak yang ada pada dirinya. Arsitektur merupakan ungkapan konsep ruang.

\section{Simpulan}

Arsitektur (ruang) dibentuk oleh sistem pengetahuan yang berkembang dinamis. Kosmologi memegang peran penting dalam terbentuknya arsitektur. Untuk dapat membedah kosmologi dalam arsitektur diperlukan pemahaman yang menyeluruh yang 
melibatkan berbagai disiplin ilmu, antara lain: filsafat, astronomi, geografi, psikologi, antropologi, sosiologi, sejarah, dan hermeneutika.

\section{Daftar Pustaka}

Anwarsy. 2010. Pengantar Kajian Interdisipliner. anwarsy.wordpress.com/2010/01/26/kajian-interdisipliner. Di-download tanggal 16 Nopember 2016

Badillo. Noe. 2011. Dialectics of Cosmology: A Hermeneutical Study of John Hendrix's Architectural Forms and Philosophical Structures. Jurnal ARH 511B, 3/24/2011.

Barker, Roger Garlock. 1968. Ecological Psychology: Concepts and Methods for Studying The Environment of Human Behavior. Palo Alto: Stanford University Press.

Blanchard, K. 2010. Maya in the Mountains: Ecology and Cosmology in The Rocks and Caves of Highland Guatemala.

https://apps.carleton.edu/curricular/ocs/guatemala/assets/Blanchard 2010.pdf.

Di-download tanggal 4 Mei 2014

Blier, S.P. 1987. The Anatomy of Architecture. Cambridge: Cambridge University Press.

Kaelan, H. 2012. Metode Penelitian Kualitatif Interdisipliner. Yogyakarta: Paradigma.

Kak, S. 2002. Space and Cosmology in the Hindu Temple. Vaastu Kaushal: International Symposium on Science and Technology in Ancient Indian Monuments. New Delhi, November 16-17 2002.

Kartono, J.L. 2005. Konsep Ruang Tradisional Jawa dalam Konteks Budaya. Dimensi Interior. Vol 3(2).

Kent, S. 1990. Behavioral Convention and Archaeology. Domestics Architecture and the Use of Space: an interdisciplinary and cross-cultural study. Cambridge: Cambridge University Press.

Lang, J.T. 1987. Creating Architectural Theory: The Role of the Behavioral Sciences in Environmental Design. New York: Van Nostrand Reinhold.

Lu, Y., Bozovic-Stamenovic. 2004. Built Spaces: The Cultural Shaping Of Architectural And Urban Space. Wolkenkuckucisheim - Cloud- Cuckoo Land - Vozdushnyi Zamok 01/2004, Vol 9(1) November 2004.

Mashuri. 2010. Perwujudan Konsep dan Nilai-Nilai Kosmologis pada Bangunan Rumah Tradisional Toraja. Jurnal RUANG. Vol 3(1) Maret 2010.

McHarg, I.L. 1992. Design with Nature. USA: John Wiley \& Sons.

Muhararam, A. 2013. 10 Alasan untuk Melakukan Kajian Interdisiplin xa.yimg.com/kq/groups/15524289/1408412046/name/10. Di-download tanggal 20 Nopember 2013.

Muntasyir, R. 2011. Model Interdisipliner dalam Penelitian Filsafat. mustansyir.blogspot.com/2011/11/metode-interdisipliner.html. Di-download tanggal 20 Nopember 2013.

Nelson, B. N., Lekson, S. H., Šprajc, I., \& Sassaman, K. E. 2010. Shaping Space: Built Space, Landscape, and Cosmology in Four Regions. In Prepared by the Built Space/Environment Working Group for the Santa Fe Institute Workshop on" Cosmology \& Society in the Ancient Amerindian World.

Pangarsa, G.W. 2007. Merah Putih Arsitektur Nusantara. Yogyakarta: Andi Offset

Rapoport, A. 1975. Australian Aborigines and the Definition of Place. Senior Lecturer School of Architecture University of Sydney.

Rapoport, A. 1989. House Form and Culture. Prentice Hall.

Russel, A., Wendy, et.all. 2008. Transdisciplinarity: Context, Contradictions and Capacity. Futures 40. 
Sprajc, I. 2009. Astronomical And Cosmological Aspects of Maya Architecture and Urbanis. Cosmology Across Cultures; ASP Conference Series Vol. 409. Editor: J.A. Rubino-Martin, J.A. Belmonte, F. Prada dan A. Alberdi.

Sudikan, S.Y. 2015. Pendekatan Interdisipliner, Multidisipliner, dan Transdisipliner dalam Studi Sastra. Paramasastra, 2(1).

Sumalyo, Y. 2001. Kosmologi dalam Arsitektur Toraja. Dimensi Teknik Arsitektur 29(1) pp.64-74.

Tuan, Y. F. 1975. Place: an Experiential Perspective. Geographical Review, pp. 151-165.

Tuan, Y. F. 1979. Space and Place: The Perspective of Experience. University of Minnesota Press.

Wesnawa, I.G.A. 2010. Penerapan Konsep Tri Hita Karana dalam Lingkungan Permukiman Perdesaan (Kasus Kabupaten Badung Provinsi Bali). Jurnal Bumi Lestari 10(2), pp.295-301.

Widayat, R. 2004. Krobongan Ruang Sakral Rumah Tradisi Jawa. Jurnal Dimensi Interior, 2(1).

Widyatasari, S. 2002. Tata Ruang Rumah Bangsawan Yogyakarta. Dimensi Teknik Arsitektur, 30(2), pp.122-132.

Wongphyat, W. Spatial Anthropology of Thai-Islamic Dwellings in Eastern Bangkok. Journal of Asian Architecture and Building Engineering, pp.354.

Xu, P. 1998. Feng Shui Models Structured Traditional Beijing Courtyard Houses. Journal of Architectural and Planning Research 15(4). 